\section{Descendientes de africanos en la Región de las Américas y equidad en materia de salud}

\author{
Cristina Torres ${ }^{1}$
}

Palabras clave: etnia, equidad en salud, grupos minoritarios, Américas.

\footnotetext{
Programa de Políticas Públicas y Salud, División de Salud y Desarrollo Humano, Organización Panamericana de la Salud, Washington, D.C., Estados Unidos de América. Dirección postal: 525 23rd St., N.W., Washington, D.C. 20037, Estados Unidos de América. Tel., (202) 974-3217, fax: (202) 974-3675.

2 En el marco de este trabajo se usarán "étnico" y "racial" como sinónimos. La Organización Panamericana de la Salud, en tanto forma parte del sistema de las Naciones Unidas, considera que la raza humana es una sola y que las diferencias entre personas son de carácter cultural y simbólico. Se dan más elementos conceptuales sobre el tema en la referencia 1. De todas maneras mantenemos los dos términos, dado que en muchos países se opta por una distinción entre ambos conceptos, reservando "raza" para los descendientes de africanos y "etnia" para los pueblos originarios.

3 Iglesias E. Discurso dictado en la reunión sobre La salud de descendientes de africanos en las Américas, celebrada en la Organización Panamericana de la Salud, Washington, D.C., del 18 al 20 de junio de 2001. (En preparación).
}

La Región de las Américas y el Caribe presenta una realidad demográfica compleja desde el punto de vista de su composición étnica y racial. ${ }^{2}$ La mayoría de su población actual tiene ascendentes fuera de la Región, lo cual se refleja en su desarrollo social, político y económico. Uno de esos segmentos poblacionales está constituido por los descendientes de africanos, quienes según estimaciones recientes, alcanzan cerca de 150 millones de personas y constituyen la mayor minoría étnica del continente, representando $30 \%$ de la población total de la Región. Son, de hecho, tres veces más numerosos que los descendientes de los pueblos originarios de América (2).

Los países de América Latina con la mayor proporción de población descendiente de africanos son Haití (95\%), República Dominicana (más de $84 \%)$, Cuba (62\%) y Brasil (46\%). Este último país es - aun a la luz de los estimados más conservadores- el que tiene la mayor población de origen africano de la Región, con cálculos que oscilan entre 73 y 111 millones de personas. Le siguen Colombia $(30 \%)$ y Estados Unidos (12\%), país que a pesar de esta proporción relativamente baja, ocupa el segundo lugar en términos absolutos, con 30 millones de afroestadounidenses.

Los descendientes de africanos en la mayoría de los países de la Región comparten características étnicas comunes, tanto por sus orígenes como por sus condiciones de vida de alta vulnerabilidad - excepto en los países del Caribe anglófonocomo consecuencia del desarrollo político y social de la Región.

"En momentos en que el mundo entero se preocupa del tema de la pobreza, no reconocer - como ha pasado durante décadas y siglosque el grueso de los problemas de la pobreza está concentrado en los bolsones de exclusión, básicamente étnicos, que existen en América Latina, significa esconder una realidad que es realmente una afrenta de orden ético y una forma velada de evitar nuestro compromiso de trabajar por una sociedad más igualitaria". ${ }^{3}$

Como es por todos sabido, el desarrollo del Norte y del Sur del continente americano ha presentado matices importantes en el tratamiento de las minorías étnicas a partir de la época colonial, lo que dejó su impronta en las relaciones entre los grupos poblacionales mayoritarios y las minorías étnicas, y también en la forma en que el estado se rela- 
cionó con los grupos minoritarios en los diferentes países.

A diferencia de lo que ocurrió en Estados Unidos a partir de los años sesenta del siglo $\mathrm{xX}$, cuando se modificó el paradigma de la relación entre los grupos sociales, en los países de América Latina no se visualizó el origen étnico-racial como barrera a la integración, sino por el contrario, se pensó que el problema se superaba con el mestizaje y se aspiró a construir una "democracia racial", sin tomar conciencia real del peso de la discriminación y el racismo en el seno de la cultura latinoamericana como legado de un pasado esclavista.

Recientemente, la pobreza y su estrecha relación con la salud, junto con sus implicaciones éticas y económicas, han estado en el centro de las agendas de cooperación internacional. Mampheta Rampehele, director ejecutivo del Banco Mundial, lo expresa en su justa dimensión: "Inequity is becoming less and less affordable, not only for poor people, but for the global community as a whole. The world can no longer turn a blind eye to the cost of diseases that poverty generates" (3).

En una primera etapa, el fenómeno de la pobreza en la que viven importantes segmentos poblacionales se analizó independientemente del factor étnico, tomando en cuenta la pobreza y no a los sujetos que la padecían. Esto postergó la percepción de que la ascendencia étnica es un factor macrodeterminante que establece no solo condiciones de vida que generan diferencias entre las personas, sino que también inciden en su salud y en su acceso a los servicios.

Felizmente, esta situación comenzó a cambiar de manera acelerada a partir de la ultima década del siglo $\mathrm{XX}$, y en varios ámbitos nacionales e internacionales ya se considera que "it is simplistic to say that all of the differences that are attributed to ethnicity are poverty-related; it's really simplistic to say that. What we know now-the data is accumulating-is that it is not so; even within social gradients you will find that there are differences as a result of ethnicity". ${ }^{4}$ Las pruebas ponen de manifiesto que a iguales niveles de ingresos, las minorías étnicas acceden menos a los servicios o tienen peores indicadores de salud, y que, por otra parte, la mayoría de los grupos étnicos minoritarios se encuentran en los bolsones de pobreza. Se concluye entonces que para combatir eficazmente la pobreza y reducirla, es necesario que en el diseño de políticas se contemple el tema étnico.

La pertinencia de esta perspectiva no es solo para los países en desarrollo. También se aplica y ha

\footnotetext{
Alleyne GAO. Discurso dictado en la reunión sobre La salud de descendientes de africanos en las Américas, celebrada en la Organización Panamericana de la Salud, Washington, D.C., del 18 al 20 de junio de 2001. (En preparación).
}

sido adoptada por un país tan desarrollado como los Estados Unidos. En 1998, el entonces presidente William Clinton anunció la intención de su administración de eliminar las desigualdades raciales y étnicas en materia de salud. La iniciativa "Healthy People 2010", lanzada en enero del año 2000 por la Secretaria de Servicios de Salud, Donna Shalala, y el Jefe de Sanidad, David Satcher, plantea como objetivo central reducir las inequidades en las condiciones de salud y el acceso a los servicios asistenciales, y establece áreas especificas de atención: mortalidad infantil, detección temprana del cáncer, enfermedades cardiovasculares, diabetes, infección por VIH o sida, y vacunación. Esta iniciativa fortaleció la recolección de información estadística desagregada por raza y grupo étnico (4), como medida para garantizar su desarrollo y éxito.

"We in health have to look at social and economic status, we have to look at who gets diagnosed, we have to look at lifestyles and we have to look at disparities in care, when we try to look at disparities in outcome. We know there is no escaping the link between health and race, minorities fare worse, as we pointed out, in most instances. I did not indicate, however, that if you look at the ten top causes of death in the U.S., for nine of those ten causes, if you break it down by population group, AfricanAmericans are number one in nine of the top ten. So race plays a major role. There is an inextricable link between health and poverty: people who are poor are people who are less healthy". ${ }^{5}$

\section{LA DISCRIMINACIÓN, EL RACISMO, LA XENOFOBIA Y OTROS TIPOS DE INTOLERANCIA}

El proceso político y social que se desarrolló en el marco de la preparación de la Conferencia Mundial organizada por las Naciones Unidas (ONU) contra la discriminación, el racismo, la xenofobia y otros tipos de intolerancia ${ }^{6}$ fue extremadamente positivo para la Región de las Américas en la medida en que permitió un espacio para repensar las políticas desde una perspectiva de equidad $y$, además, facilitó la organización de las minorías étnicas, que tuvieron una interlocución activa. El resultado de este proceso fue la incorporación de la lucha contra la exclusión social de los grupos étnicos en la agenda política y social, y la constitución y participación de nuevos actores sociales en representación de estos grupos postergados, que se

\footnotetext{
5 Noonan A. Discurso dictado en la reunión sobre La salud de descendientes de africanos en las Américas, celebrada en la Organización Panamericana de la Salud, Washington, D.C., del 18 al 20 de junio de 2001. (En preparación).

6 Se realizaron intensas actividades en los diferentes países en preparación de la Conferencia y entre 2000-2001 se convocaron cuatro reuniones regionales en Estrasburgo, Santiago, Dakar y Teherán.
} 
afianzan en una compleja y sostenida fase de discusión desde hace casi dos años.

En el período de 1999-2001, bajo el auspicio del Alto Comisionado de Derechos Humanos de las Naciones Unidas (UNHCHR), se revisaron los paradigmas de las relaciones entre los grupos humanos a escala mundial, y ello condujo a la identificación en la Región de grupos humanos cuyos orígenes se remontan a los pueblos originarios y a otros de ascendencia africana, que históricamente han tenido poca participación social y política en América Latina y el Caribe.

La preparación de la Conferencia de la ONU permitió compartir un nuevo marco conceptual para analizar los problemas de exclusión y pobreza que afectan a la Región de las Américas, con la introducción de una perspectiva social e histórica que afirma que la situación de privación existente en la actualidad tiene sus raíces en las relaciones sociales que se construyeron muy tempranamente en la historia política y económica de los países del continente y que están arraigadas en la relación que la mayoría de la población estableció con los grupos humanos de diferentes orígenes étnicos.

Como lo expresara claramente Mary Robinson, Alta Comisionada de la ONU para los Derechos Humanos, "The opportunity is there for the world to engage, for the first time in the post-apartheid era, not only in an agenda of combating all forms of discrimination, but in the agenda that affirms the value of diversity and sees it as a gift rather than a threat. It will be vital to address gender and racism and harness the energies of the women's movement on this in every region. Future generations will not forgive us if we fail to rise to the challenge" (5).

La Cumbre de las Naciones Unidas que tuvo lugar en Durban, África del Sur, en agosto de 2001, produjo dos documentos - la Declaración y el Plan de Acción- con los que se aspira a facilitar la creación de una conciencia real contra las manifestaciones y las consecuencias nefastas del racismo y la discriminación, así como a establecer mecanismos para reducirlas y revertirlas.

Los grupos étnicos de mayor peso en la Región de las Américas - los descendientes de africanos y los pueblos indígenas- ocupan un lugar relevante en la Declaración y el Plan de Acción. En su Artículo 33, la Declaración expresa: "We consider it essential for all countries in the region of the Americas and all other areas of the African Diaspora to recognise the existence of their population of African descent and the cultural, economic, political and scientific contributions made by that population, and recognise the persistence of racism, racial discrimination, xenophobia and related intolerance that specifically affect them, and recognise that, in many countries, their longstanding inequality in terms of access to, inter alia, education, health care and housing has been a profound cause of the socio-economic disparities that affect them" (6).

Cabe destacar que los derechos humanos fueron tratados en la Conferencia con un significado vasto, donde tuvieron cabida los derechos sociales, y en el Artículo 31 de la Declaración, por ejemplo, los delegados gubernamentales afirman: "we also express our deep concern whenever indicators in the field of, inter alia, education, employment, health, housing, infant mortality and life expectancy for many people show a situation of disadvantage, particularly where the contributing factors include racism, racial discrimination, xenophobia and related intolerance" (6).

La Conferencia Mundial tomó en cuenta también la necesidad de actualizar las bases de datos de estadísticas vitales, ya que la información organizada por grupos étnicos es crucial para identificar los problemas y definir un diagnóstico preciso. En este sentido, en el capítulo 2 del Plan de Acción se llama a los Estados: "to collect, compile, analyse disseminate and publish reliable statistical data at the national and local levels and undertake all other related measures which are necessary to assess regularly the situation of individuals and groups of individuals who are victims of racism, racial discrimination, xenophobia, and related intolerance [...].

"Any such information shall, as appropriate, be collected with the explicit consent of the victims, based on their self-identification and in accordance with provisions on human rights [. . .]. The information should take into account economic and social indicators, including, where appropriate, health and health status, infant and mother mortality, life expectancy literacy, education, employment, housing, land ownership, mental and physical health care, water, sanitation and economic development policies with a view to closing the existing gap in social and economic conditions)."

La preocupación de los delegados gubernamentales por el tema de reducir las brechas en las condiciones de salud y en el acceso a los servicios asistenciales de los grupos que han sido o pueden ser objeto de prácticas discriminatorias se refleja en el Plan de Acción, bajo el acápite de Salud y medio ambiente (Artículos 109-111). En ellos se insta a los Gobiernos a que -individualmente o mediante la cooperación internacional- adopten medidas para garantizar el derecho de cada persona a gozar del más alto nivel de salud física y mental posible, y a tratar de eliminar desigualdades relacionadas con la salud resultantes de la discriminación, el racismo, la xenofobia y otras formas de intolerancia (7).

El Artículo 110 del Plan de Acción alienta a los Estados, las organizaciones no gubernamentales $\mathrm{y}$ al sector privado, a:

- proveer mecanismos efectivos para monitorear el desarrollo de los sistemas de salud con vistas a 
eliminar actos de discriminación racista o xenófoba, y garantizar la existencia de instrumentos de políticas fuertes - como las leyes - si fuera necesario

- lograr el acceso equitativo a la atención de salud -en el sentido más abarcador-, incluida la atención primaria

- trabajar por el aumento de la diversidad, según el origen étnico, de profesionales de la salud, y adoptar prácticas de reclutamiento que, respetando los méritos, tomen en cuenta adecuadamente la diversidad étnica

- trabajar con los profesionales de la salud con el fin de estudiar y medir el impacto de tratamientos médicos en comunidades de diferentes orígenes étnicos

- adoptar políticas y programas que incrementen las acciones de prevención del sida y de la infección por el VIH en comunidades en alto riesgo.

Por último, el Artículo 111 invita a los Estados a contemplar medidas no discriminatorias para proveer un medio ambiente seguro y saludable para personas o grupos que son víctimas de la discriminación racial, y en particular para proveer acceso a la información pública sobre la salud y el medio ambiente, divulgar tecnologías y prácticas eficaces para mejorarlas, así como tomar las medidas necesarias de carácter paliativo para limpiar zonas contaminadas y, cuando sea necesario, reubicar a la comunidad afectada teniendo en cuenta sus opiniones y deseos.

La Conferencia Mundial dirigió sus recomendaciones a un espectro amplio de actores del Estado (gobiernos, congresos), de la sociedad civil (comunidades y organizaciones no gubernamentales) y de la comunidad internacional. En lo que se refiere a la salud, pide a "WHO and other relevant international organizations to promote and develop activities for the recognition of the impact of racism, racial discrimination, xenophobia, and related intolerance as significant social determinants of physical and mental health".

Este proceso moviliza también a las instituciones financieras internacionales y a las agencias de cooperación, que durante los años 2000 y 2001 comenzaron a coordinar actividades en torno al tema de la inclusión social y sus aspectos étnicos y raciales. Por una parte, la OPS y la OMS se movilizaron en el seguimiento de las diferentes etapas de la preparación de la Conferencia (conferencias regionales, encuentros de ONG, grupos de expertos), fundamentalmente en la Región de las Américas, donde el tema de la diáspora africana tiene más significado político y realidad social. Por otra parte, el Banco Mundial y el Banco Interamericano de Desarrollo, junto con la Fundación Ford y la organización Inter-American Dialogue, iniciaron en junio del año 2000 un empeño por crear un espacio de consulta y articulación sobre el tema de la "raza en América Latina", que se consolidó unos meses más tarde con el nombre de Inter-Agency Consultation on Race (IAC) $)^{7}$. Finalmente, las iniciativas y los esfuerzos confluyeron, lo que permitió que la OPS se incorporara como miembro activo de la IAC. De esta manera cristalizó el anhelo de coordinación institucional en las actividades de junio de 2001 en Washington, D.C., donde expertos y activistas patrocinados por las instituciones miembros de la IAC se reunieron para analizar diferentes problemas relacionados con la exclusión racial y para elaborar recomendaciones que guiaran la cooperación internacional.

\section{LOS CAMBIOS EN EL ÁMBITO JURÍDICO Y EL PAPEL DE LOS PARLAMENTOS}

Como se señaló anteriormente, muchos de los países de América Latina no habían tomado en cuenta el tema de la situación específica de los descendientes de africanos y otras minorías étnicas, debido a que consideraban el tema resuelto mediante el otorgamiento de los derechos formales. Todas las constituciones de la Región establecen el principio de igualdad de los ciudadanos ante la ley, prescriben la discriminación por motivo de origen, raza, sexo, idioma, religión, opinión, condición económica o de cualquier índole. Este espíritu, que primó en la legislación latinoamericana, encontró formas muy amplias de presentar el tema en el capítulo de los derechos fundamentales. Formulaciones similares a la mencionada más arriba - que pertenece a Panamá- aparecen en las constituciones de Colombia, Ecuador, El Salvador, Nicaragua y Perú.

Otras cartas magnas son más sintéticas y por lo tanto restringidas, como la de Chile, según la cual "en Chile no hay persona ni grupo privilegiado [...] no hay esclavos y el que pise su territorio queda libre", o la de Costa Rica, que expresa: "todo hombre es igual ante la ley y no podrá hacerse discriminación alguna contraria a la dignidad humana". En el caso de Brasil se manifiesta que "todos los hombres son iguales ante la ley, sin distinción de cualquier naturaleza [...]". En este grupo se incluye la Constitución argentina, que establece que “en la Nación Argentina no hay esclavos, la Nación Argentina no admite prerrogativas de sangre ni de nacimiento: no hay en ella fueros personales ni títulos de nobleza. Todos los habitantes son iguales ante la ley [. . . ]".

Gracias a los auspicios de Inter-American Dialogue, la IAC dispone
de una secretaría situada en 1211 Connecticut Avenue, Suite 510, Washington, D.C., EE. UU. 
Otras, como la de Honduras, son más enfáticas: "Todos los hombres nacen libres e iguales en derechos; se declara punible toda discriminación por motivo de sexo, raza, clase o cualquier otra lesiva a la dignidad humana".

Estos preceptos contenidos en las constituciones marcan un punto de partida, pero los países también han adoptado otros mecanismos jurídicos, tales como las convenciones, convenios y tratados, que se han generado a partir de foros internacionales y contribuyen al establecimiento de la equidad social y al reconocimiento de los derechos económicos y sociales. Los parlamentos desempeñan un papel fundamental en este proceso, ya que deben analizar estos instrumentos y aprobarlos antes de su ratificación por el poder ejecutivo.

En este rubro cabe recordar la Convención Internacional sobre la eliminación de todas las formas de discriminación racial, aprobada por la Asamblea General de las Naciones Unidas en 1965 y abierta a la ratificación por los países. Hasta la fecha, 26 países de América Latina y el Caribe la han ratificado. ${ }^{8}$

Por su parte, la Organización de Estados Americanos (OEA) también ha trabajado sistemáticamente en el tema y un antecedente interesante es la Convención Americana sobre Derechos Humanos, por la cual la Comisión Interamericana de Derechos Humanos trabajó desde 1967 y auspició su preparación y ratificación. En su Artículo 1, la Convención establece que los Estados se comprometen a respetar los derechos humanos de las personas sin discriminación alguna por motivo de raza, color, sexo, idioma, religión, opiniones políticas o de cualquier índole, origen nacional o social, posición económica, nacimiento o cualquier otra condición social. En el Artículo 6 de la misma Convención se prohíben la esclavitud y la servidumbre, entendidas como la perdida de libertad acompañada de trabajos forzosos. Basándose en una propuesta de Brasil ratificada por la Asamblea General en 2001, se prepara el texto de una Convención Americana para prevenir, penar y erradicar el racismo y todas las formas de discriminación e intolerancia. Esta convención deberá definir los actos racistas como actos penales e instará a los Estados a adoptar estrategias y políticas para combatir la discriminación y proveer medidas compensatorias y programas que promuevan la igualdad. Anteriormente, la OEA trabajó en el texto del proyecto de la Declaración americana de los derechos de los pueblos indígenas, que fue aprobada en 1997 por la Comisión

\footnotetext{
8 Argentina, Bahamas, Barbados, Bolivia, Brasil, Chile, Colombia, Costa Rica, Cuba, Ecuador, El Salvador, Granada, Guatemala, Guyana, Haití, Jamaica, México, Nicaragua, Panamá, Perú, República Dominicana, St. Lucia, San Vicente y las Granadinas, Trinidad y Tabago, Uruguay y Venezuela.
}

Interamericana de Derechos Humanos. Cabe destacar que el concepto de "indígena" incluye las comunidades con fuerte ascendencia africana, como los garífunas y los miskitos, en Centroamérica, y a los habitantes del Chocó, en Colombia, y de Esmeraldas, en Ecuador.

En relación con la salud se incluye un artículo especial que establece que "estos pueblos tendrán derecho al reconocimiento legal y a la práctica de su medicina tradicional, tratamiento, farmacología, prácticas y promoción de la salud, incluyendo la prevención y rehabilitación". ${ }^{9}$

También se debe destacar la intensa labor de la Organización Internacional del Trabajo desde fines de los años ochenta en la preparación, aprobación y ratificación del Convenio 169 "sobre pueblos indígenas y tribales en países independientes", ratificado ya por Argentina, Bolivia, Colombia, Costa Rica, Ecuador, Guatemala, Honduras, México, Paraguay y Perú. Según este Convenio, se reconoce a los pueblos indígenas y tribales el derecho a la propiedad y posesión de las tierras que ocupan. Este empeño ha tenido como corolario que en los últimos años algunos países hayan avanzado en una legislación que puede ser considerada modelo. Por ejemplo, la Ley 70 de Colombia, de 1993, en su Artículo 1 establece que el objetivo de esa ley es "reconocer a las comunidades negras que han venido ocupando tierras baldías en las zonas rurales ribereñas de los ríos de la cuenca del Pacífico, de acuerdo con sus prácticas tradicionales de producción, el derecho a la propiedad colectiva, [. . .].

"Así mismo tiene como propósito establecer mecanismos para la protección de la identidad cultural y de los derechos de las comunidades negras de Colombia, como grupo étnico, y el fomento de su desarrollo económico y social, con el fin de garantizar que esas comunidades obtengan condiciones reales de igualdad de oportunidades frente al resto de la sociedad colombiana." La Ley cubre un espectro amplio de temas, desde la tenencia y posesión de las tierras, hasta el establecimiento de un cupo de dos representantes en la Cámara Baja del Congreso Nacional y la creación de una dirección de asuntos para las comunidades negras en el Consejo de Política Económica y Social, e incluso temas de protección de la identidad cultural, el desarrollo social, el acceso al crédito, la capacitación técnica y la educación. En el articulo 37 se establece que "el Estado debe adoptar medidas que permitan a las comunidades negras conocer sus derechos y obligaciones, especialmente en lo que atañe al trabajo, a

\footnotetext{
9 Kreimer O. Discurso dictado en la reunión sobre La salud de descendientes de africanos en las Américas, celebrada en la Organización Panamericana de la Salud, Washington, D.C., del 18 al 20 de junio de 2001. (En preparación).
} 
las posibilidades económicas, a la educación y salud, a los servicios sociales y a los derechos que surjan de la Constitución y las leyes".

Otros países también han estado activos en el reconocimiento de los derechos específicos de las comunidades de ascendencia africana, como es el caso de Ecuador, que ha creado una comisión parlamentaria para asuntos étnicos, dedicada a estudiar un anteproyecto de ley orgánica de nacionalidades y pueblos indígenas que contiene un capítulo sobre los pueblos negros. La ley orgánica tiene como propósito convertirse en el mecanismo legal idóneo para la aplicación efectiva de los derechos humanos en ese país, y recoge además las recomendaciones emanadas de los instrumentos jurídicos internacionales que ya han sido ratificados por Ecuador, como los ya enunciados.

En relación con la salud, el anteproyecto establece en sus Artículos 7 y 8 que se deberá crear un Consejo de Desarrollo de las Nacionalidades y Pueblos del Ecuador (CODENPE) como órgano encargado de planificar proyectos y programas de desarrollo humano, brindar servicios básicos de salud, dar atención a la salud y al bienestar social y preservar el medio ambiente en las circunscripciones territoriales. ${ }^{10}$

Naturalmente, es necesario destacar también la labor de Brasil en el campo político y social en favor de los grupos de ascendencia africana. Existen varios proyectos de ley que fueron llevados al Congreso para su discusión y que no fueron aprobados. Tal es el caso de la iniciativa para introducir la disciplina Historia de África en los currículos escolares, que fue presentada por el diputado Paulo Paim, en 1988; el proyecto de ley sobre la inclusión de la presencia de descendientes de africanos en la producción de emisoras de televisión y otros medios de comunicación, presentado en 1998; el de la prohibición de la expresión "buena apariencia" en los anuncios de reclutamiento (1997); o el proyecto de ley 3614/97 que establece como obligatoria la identificación étnico-racial en los servicios de salud públicos y privados (8). Lamentablemente, estos y otros proyectos presentados no siempre han logrado superar las controversias en el ámbito jurídico y ser aprobados en ambas cámaras para convertirse en ley.

Pero evidentemente, la coyuntura en el nuevo milenio es más propicia para este tipo de iniciativas. En julio de 2001, un grupo de parlamentarios negros se reunió en Salvador, Bahía, y firmó una declaración en virtud de la cual asume una serie de

\footnotetext{
10 "La circunscripción territorial es el espacio territorial en el que se encuentran asentadas ancestralmente una o varias comunidades (...) donde desarrollan sus particulares formas de vida." (Artículo 1).
}

compromisos en defensa de los grupos de ascendencia africana y en favor de reducir las desigualdades de origen racista: la creación de un Fondo Nacional de Reparación, la incorporación de metas para la promoción de la población negra brasileña en todos los programas de acción gubernamental, la inclusión de dotaciones presupuestarias en todas las leyes presupuestarias con el objetivo de reducir las inequidades, el desarrollo de una acción permanente para la formación de la autoestima y la recuperación del legado histórico.

\section{DIFERENCIAS EN LA SITUACIÓN DE SALUD Y EQUIDAD DEL ACCESO A LOS SERVICIOS}

En la inmensa mayoría de los países de la Región, la información epidemiológica según el origen étnico o racial es aún muy fragmentaria, dado que las estadísticas de salud no consideran esta variable. Una excepción es Estados Unidos, donde la recolección de información para diferentes grupos étnicos es legal desde 1964 (4).

Hay dos posibles aproximaciones para producir un diagnóstico preliminar que aliente a las autoridades sanitarias nacionales a considerar la posibilidad de dedicar trabajo y recursos a perfeccionar las bases de datos, así como a comenzar a diseñar programas y políticas que tomen en consideración las etnias y razas. La primera, de índole geográfica, busca analizar comparativamente los datos de las regiones, provincias y estados donde un porcentaje alto de la población es de un origen étnico particular y compararlo con la media nacional. La segunda consiste en analizar la información recolectada en las encuestas domiciliarias, que en algunos países solicitan a las personas entrevistadas que se autoclasifiquen según su extracción étnica. De esta forma se puede disponer de información sobre las condiciones de vida y trabajo desagregada según grupo étnico y raza, incluidos algunos problemas de salud.

Además de las fuentes citadas anteriormente, la OPS ha estado recopilando datos a partir de estudios publicados sobre el tema en los diferentes países de la Región, con vistas a disponer de las pruebas necesarias para adoptar políticas orientadas a superar las inequidades que impiden el acceso de todos a la buena salud. Esta información está disponible en varias de las publicaciones de la Organización (9-11), motivo por el cual en el presente artículo solo ilustraremos la situación de algunos países que no fueron incluidos en las publicaciones anteriores.

La posibilidad de morir de un niño colombiano descendiente de africanos en Chocó - departamento con una población de ancestros africanos 
CUADRO 1. Comportamiento de algunos indicadores demográficos seleccionados. Departamento del Chocó, Colombia

\begin{tabular}{lcc}
\hline \multicolumn{1}{c}{ Indicador } & Chocó & Colombia \\
\hline $\begin{array}{l}\text { Esperanza de vida al nacer } \\
\text { (en años) }\end{array}$ & 66,78 & 72,17 \\
$\quad$ Hombres & 63,61 & 69,17 \\
$\quad$ Mujeres & 70,10 & 75,32 \\
$\begin{array}{l}\text { Mortalidad infantil } \\
\text { (por 1 000 nacidos vivos) }\end{array}$ & 89,13 & 25,83 \\
$\begin{array}{l}\text { Mortalidad perinatal } \\
\text { (por 1 000 nacidos vivos) }\end{array}$ & 65,70 & 17,50 \\
$\begin{array}{l}\text { Mortalidad materna } \\
\text { (por 1 000 nacidos vivos) }\end{array}$ & 199,00 & 80,00 \\
\hline Fuentes: Referencias 12 y 13. & &
\end{tabular}

cercana al 100\% - es tres veces más alta que la de sus compatriotas nacidos en cualquier otro lugar de Colombia. Las diferencias según las tasas de mortalidad perinatal y materna son todavía más marcadas (cuadro 1).

Naturalmente, esta situación es coherente con los indicadores socioeconómicos calculados según las necesidades básicas insatisfechas. Chocó presenta los indicadores de analfabetismo más altos del país, supera el promedio nacional de inasistencia escolar y tiene un porcentaje de servicios inadecuados siete veces más alto que el promedio nacional $(31,0$ frente a 4,8). Existen carencias en la cobertura de los servicios de vacunación, como se observa en el cuadro 2.

Esta situación se repite en Nicaragua. Según datos de 1998 de fuentes oficiales del Ministerio de Salud (14), la tasa de mortalidad materna en los estados autónomos de la Región Autónoma del Atlántico Norte (RAAN) y la Región Autónoma del Atlántico Sur (RAAS) —en los que se asientan comunidades de minorías étnicas- es de 236 y $192 \times$ 100000 nacidos vivos, respectivamente, frente a un promedio nacional de 106 por 100000 nacidos vivos. Estas regiones autónomas también presentan diferencias en cuanto a los indicadores de morbilidad (cuadro 3) que coinciden con las observadas en otros países. En la RAAN y la RAAS se presentan los mayores índices de pobreza, calculados según las necesidades básicas insatisfechas, con 95,6\%, frente a un promedio nacional de $82,3 \%$.

Esmeraldas, provincia de Ecuador donde también se asienta una comunidad importante de ascendencia africana, es otro ejemplo. Según datos del año 2001 de fuentes oficiales del Ministerio de Salud Pública y del Instituto Nacional de Estadística y Censo (INEC), el cuadro es semejante al descrito anteriormente: la mortalidad materna para Esmeraldas es de 109,7 por 100000 nacidos vivos, mientras que para el total del país es de 68,5 (15). La mortalidad infantil estimada también presenta disparidades: en Esmeraldas 40 por 1000 nacidos vivos, frente a un promedio nacional de 30 por 1000 nacidos vivos. El acceso a los servicios también pone de manifiesto la desigualdad de oportunidades entre los habitantes de Esmeraldas y los del resto del país, como evidencian los datos sobre la disponibilidad de los servicios básicos (cuadro 4).

Otra situación que ha merecido especial atención es la de Brasil, por tratarse de una sociedad civil organizada y muy activa, así como por los datos estadísticos provenientes de la Encuesta Demográfica Nacional (PNAD), que ha incorporado la variable raza-etnia y que publica sistemáticamente sus resultados. Según esta fuente, los descendientes de africanos (pardos y pretos) representan el $45 \%$ de la población brasileña y constituyen la mayor minoría étnica, con una concentración geográfica en el Norte y Noreste del país. En varios estados de la federación, los descendientes de africanos representan más del 70\% de la población (Amapa, Amazonas, Bahia, Maranhão, Para, Piaui, Roraima, Sergipe y Tocantis). Al igual que en los casos citados anteriormente, la distribución de la población descendiente de africanos se corresponde con las zonas de menos desarrollo económico y social. Los indicadores de salud también reflejan desigualdades significativas. Por ejemplo, la mortalidad infantil en menores de 5 años es mayor en los descendientes de africanos (102,1 frente a 82,8 por 1000 nacidos vivos en los blancos). En algunas regiones del país, este indicador también se mantiene más alto que la media nacional (en el Sudeste: 52,7 frente a 30,9; en el Sur: 47,7 frente a 34,8$)(16)$.

CUADRO 2. Cobertura de vacunación (\%), Chocó y Colombia

\begin{tabular}{lcccccc}
\hline Territorio & Polio & DPT & BCG & Hepatitis & H. influenzae Ba & Triple viral \\
\hline Chocó & 58 & 54 & 85 & 59 & 49 & 57 \\
Colombia & 82 & 78 & 90 & 77 & 65 & 79 \\
\hline $\begin{array}{l}\text { Fuente: Referencia 12. } \\
\text { a Haemophilus influenzae B. }\end{array}$ & & & & &
\end{tabular}


CUADRO 3. Tasa de morbilidad por 10000 habitantes, RAAN $^{\mathrm{a}}$ y RAAS $^{\mathrm{b}}$, Nicaragua

\begin{tabular}{lcccc}
\hline Territorio & EDA $^{\mathrm{c}}$ & IRA $^{\mathrm{d}}$ & Cólera & Malaria \\
\hline RAAN & 543,60 & 1874,34 & 7,35 & 256,85 \\
RAAS & 876,55 & 4312,62 & 1,15 & 159,85 \\
$\begin{array}{l}\text { Total } \\
\quad \text { del país }\end{array}$ & 450,02 & 2962,86 & 1,10 & 74,15 \\
\hline $\begin{array}{l}\text { Fuente: Referencia 14. } \\
\text { a Región Autónoma del Atlántico Norte. }\end{array}$ & & \\
b Región Autónoma del Atlántico Sur. \\
$\begin{array}{l}\text { c Enfermedades diarreicas agudas. } \\
\text { d Infecciones respiratorias agudas. }\end{array}$
\end{tabular}

CUADRO 4. Disponibilidad de agua potable, alcantarillado y letrinas (\%). Esmeraldas, Ecuador, 1998

\begin{tabular}{lccc}
\hline \multicolumn{1}{c}{ Territorio } & Agua potable & Alcantarillado & Letrinas \\
\hline Esmeraldas rural & 29,7 & 4,4 & 30,3 \\
Esmeraldas & & & \\
$\quad$ urbano & 86,4 & 45,3 & 13,6 \\
Nacional rural & 51,4 & 10,4 & 26,6 \\
Nacional urbano & 81,5 & 61,4 & 9,1 \\
\hline
\end{tabular}

Fuente: Referencia 15

Otros indicadores, como el acceso a agua potable, alcantarillado, recolección de residuos y electricidad, ponen de manifiesto que en todas las regiones de Brasil los descendientes de africanos tienen restricciones para el acceso a estos servicios. A partir de estos datos se ha calculado que el índice de desarrollo humano (IDH) para el conjunto de la población brasileña es de 0,796 , mientras que para los brasileños descendientes de africanos el índice es de apenas 0,573, el más bajo de América Latina, con la excepción de Nicaragua, cuyo índice es de 0,568 . Esto representa "una triste situación para el paraíso de la democracia racial" (16). Estudios académicos y de organizaciones no gubernamentales realizados con la cooperación internacional aportan datos que complementan este diagnóstico e identifican dos tipos de problemas asociados a la salud que son más frecuentes en la población brasileña descendiente de africanos (17):

1. los determinados genéticamente, tales como la anemia falciforme, la hipertensión y la diabetes

2. los derivados de las condiciones socioeconómicas desfavorables y la discriminación, tales como la desnutrición, la violencia, los abortos sépticos, las enfermedades ocupacionales, y el sida y la infección por VIH.
Estos problemas se ven agravados por las dificultades para acceder a los servicios de salud de personas con hipotensión arterial, diabetes mellitus, enfermedad coronaria, insuficiencia renal crónica, cáncer y miomas. Para poder lograr una mayor equidad en salud, es necesario formular políticas que permitan corregir la actual inequidad étnico-racial, lo que sin duda redundará en la reducción de la pobreza.

\section{Conclusiones y perspectivas}

El contexto internacional — definido por los compromisos asumidos por los gobiernos de la Región en la Conferencia de Durban, la movilización de la sociedad civil en representación de las comunidades de descendientes de africanos y la articulación de las agencias de cooperación- es extremadamente favorable para las acciones que conduzcan a reducir las inequidades de salud derivadas de diferencias étnico-raciales. De hecho, ofrece una ventana de oportunidades para que el sector de la salud en los diferentes países de la Región actualice el diagnóstico de la situación, así como la definición, discusión y adopción de instrumentos de políticas para superar los sesgos derivados de la discriminación racial. Los lineamientos para establecer políticas de salud en este campo - tal como lo recomendaran los expertos en la consulta de junio de 2001- deben ser intersectoriales e integrales, orientados a corregir este tipo de inequidades en el sector de la salud.

Dado lo sensible del tema desde los puntos de vista social y político, estos lineamientos deben basarse en pruebas, por lo que es necesario mejorar la información estadística y epidemiológica. Otros componentes medulares son la capacitación de profesionales, el desarrollo de acciones de promoción y prevención orientadas a llegar a las minorías de ascendencia africana, y el desarrollo de programas dirigidos a atender los problemas de salud de comunidades específicas.

En cumplimiento del mandato de la Cumbre de las Naciones Unidas, una de las actividades prioritarias del Programa de Políticas y Salud de la OPS para el año 2002 será colaborar estrechamente con los países a fin de mejorar las bases de información que contemplen el origen étnico-racial. Otra será recopilar ejemplos de las experiencias favorables de programas y planes en comunidades de ascendencia africana. El tercer componente de la cooperación será la identificación de mecanismos apropiados para una adecuada focalización que conduzca a una redistribución positiva en el orden social. 
Por último, el paquete de actividades se completa con un esfuerzo por diseminar toda la información que existe mediante mecanismos electrónicos, además de los mecanismos empleados habitualmente para la comunicación de información.

\section{SYNOPSIS}

\section{People of African descent in the Region of the Americas and health equity}

The Region of the Americas and the Caribbean has a complex demographic profile from an ethnic and racial perspective. One of the largest groups is composed of persons of African descent, who in some countries, such as Brazil and the Dominican Republic, comprise 46 and $84 \%$ of the total population, respectively. Recent analyses of the statistics available in some countries of the Region show wide gaps in terms of living conditions and health in these communities, as well as gaps in access to health services. PAHO, through its Public Policy and Health Program, under the Division of Health and Human Development, supports sectorial efforts and those of civil organizations that aim to improve health conditions in this segment of the population, while taking into account their sociodemographic and cultural characteristics. This article briefly summarizes health conditions and access to health services in selected countries, as well as some aspects of the recent changes to the legislation in those countries. Finally, collaborative activities on the part of United Nations agencies and international financial institutions for the benefit of people of African descent and other ethnic minorities are described.

\section{REFERENCIAS}

1. Torres C. Equidad en salud, una mirada desde la perspectiva de la etnicidad. Washington, D.C.: Organización Panamericana de la Salud; 2001.

2. Alleyne GAO. Desarrollo social. Edición especial. Washington, D.C.: Banco Interamericano de Desarrollo; 2001.

3. World Bank, World Health Organization. Dying for change. Geneva: WB, WHO; 2001.

4. Perot R, Youdelman M. Racial, ethnic, and primary language data collection in the health care system: an assessment of federal policies and practices. Summit Health Institute for Research and Education, Inc. (SHIRE); September 2001. Disponible en: http://www.cmwf.org

5. Robinson M. Towards a shared vision of development: high level dialogue on race, etnicity and inclusion in Latin America and the Caribbean. Discurso pronunciado en el Banco Interamericano de Desarrollo, Washington, D.C., el 18 de junio de 2001. IADB-Banco Interamericano de Desarrollo, Washington, D.C., 2001.

6. United Nations. Declaración emitida en la World Conference Against Racism, Racial Discrimination, Xenophobia and Related Intolerance, celebrada en Dur- ban, África del Sur, del 31 de agosto al 8 de septiembre de 2001. Disponible en: http://www.unhchr.ch/html/racism. Durban.htm, 2001.

7. Hopenhayn M, Bello A. Discriminación étnico-racial y xenofobia en América Latina y el Caribe. Nueva York: Naciones Unidas, CEPAL; 2001. (Serie Políticas Sociales).

8. Cardoso EL. Organizar a pressão sobre o legislativo. En: Berquó E. População negra em destaque. São Paulo: Centro Brasileiro de Análise e Planejamento; 1998.

9. Organización Panamericana de la Salud. Equidad en salud desde la perspectiva de etnicidad, 2001. En: Salud de las Américas. Washington, D.C.; 2002. (En preparación).

10. World Health Organization. WHO's contribution to the World Conference against Racism, Racial Discrimination, Xenophobia and Related Intolerance. Health and freedom from discrimination. Geneva: WHO; 2001. (WHO Health and Human Rights, Publication Series No. 2).

11. Torres $\mathrm{C}$. La equidad en materia de salud vista con enfoque étnico. Rev Panam Salud Publica 2001;10(3)188-201.
12. Colombia, Departamento Administrativo Nacional de Estadística. Indicadores de Salud de Colombia. Santa Fe de Bogotá: DANE, OPS (Special Program for Health Analysis); 2001.

13. Fondo de las Naciones Unidas para la Infancia. Políticas públicas: maternidad sin riesgo. Santa Fe de Bogotá: UNICEF; 2001. Disponible en www.unicef.org. com.

14. Nicaragua, Ministerio de Salud. Indicadores básicos en salud de la República de Nicaragua. Managua: MINSA, OPS; 2000.

15. Ecuador, Ministerio de Salud. Situación de salud en el Ecuador. Quito: MINSA, OPS; 2001.

16. Sant Anna W, Paixão M. Desenvolvimento humano e população afrodescendente no Brasil: uma questão da raça, 1997. En: Heringer R. Desigualdades raciais: síntese de indicadores e desafios no campo das políticas públicas. Rio de Janeiro: Escola Nacional de Saúde Pública; 2001.

17. Naciones Unidas. Política nacional de saúde da população negra, uma questão de equidade. Brasilia: NU; 2001. 